\title{
Timber Inventory: A Primer for Landowners ${ }^{1}$
}

\author{
John Dooner and Michael Andreu²
}

\section{Introduction}

An integral part of any forest management program and long-term economic plan is an estimation of the current volume and value of a timber stand. Foresters approximate the amount of lumber or fiber within a stand to inform their clients on how to manage their assets and maximize revenue. The process of determining timber inventory typically involves sampling a portion of the forest and expanding these samples to calculate stand-level estimates. Commonly referred to as timber cruising, this exercise begins with planning and determining the sample allocation and type of plots, followed by basic measurement and analysis of a single tree for an estimate of stem volume. This paper outlines the process of timber cruising from initial tree-level measurements to the final total stand-level estimates and various methods for conducting the cruise.

\section{Tree Measurements \\ Diameter Measurements}

Amongst forest measurements, the most common and easily obtained tree measurement is diameter at breast height (DBH). DBH is defined as average outside bark diameter when measured on the uphill side of a tree at 4.5 feet (Avery and Burkhart 2002). DBH is commonly measured with a diameter tape ( $\mathrm{D}$-tape), which is designed to allow users to measure circumference at 4.5 feet ( 1.3 meters) and convert to a measurement of diameter (diameter $=$ circumference/ pi [where pi $=3.14]$ ). The converted diameter readings are printed on the $\mathrm{D}$-tape for quick and efficient field work. The following video shows techniques for using a D-tape: http:// www.youtube.com/watch? $=$ B67QPJa2pbM\&list=PLr5M 0QvUoAel1dKnwLvt9EF5lEtzolyTw\&index=4. DBH can also be measured using calipers or Biltmore sticks.

If the bole or stem of a tree were shaped like a true cylinder, the calculation of volume in the stem would be simple. However, most tree stems taper as you move higher in the tree. Therefore, upper diameters along the stem are also important components of volume equations. The stem diameter at the small end of the first $\log (16$ feet in the eastern United States) is often critical for determining the rate of taper in the stem and is used in many of the traditional log rules to generate volume estimates.

Because tree bark can be quite thick on some species, diameters inside the bark are used in many estimations of volume and often require the determination of the tree bark's contribution to diameter. To subtract the area occupied by the bark, the bark thickness is measured and subtracted from the diameter outside the bark. Ratios between outside and inside bark diameters at DBH are often determined and applied to outside bark diameter readings taken from points along the upper portions of the stem.

\section{Height}

Height is the second essential element for estimating tree volume. Total height or merchantable height can be measured when cruising. Total height is measured to the top of

1. This document is FOR357, one of a series of the School of Forest Resources and Conservation, UF/IFAS Extension. Original publication date February 2020. Visit the EDIS website at https://edis.ifas.ufl.edu for the currently supported version of this publication.

2. John Dooner, forester, Southern Forestry Consultants, Inc.; and Michael Andreu, associate professor, School of Forest Resources and Conservation, UF/ IFAS Extension, Gainesville, FL 32611

The Institute of Food and Agricultural Sciences (IFAS) is an Equal Opportunity Institution authorized to provide research, educational information and other services

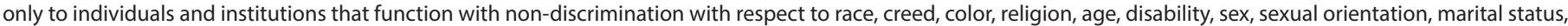

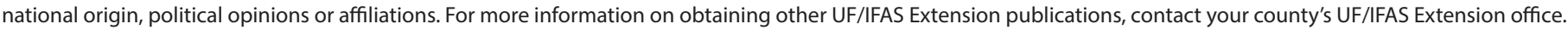
U.S. Department of Agriculture, UF/IFAS Extension Service, University of Florida, IFAS, Florida A \& M University Cooperative Extension Program, and Boards of County Commissioners Cooperating. Nick T. Place, dean for UF/IFAS Extension. 
the tree, but merchantable height is often a more informative measurement for determining the available usable wood in a tree. For most pine species in the eastern United States, merchantable heights can be measured at log lengths (16 ft) and half-log lengths (8 ft); valuable hardwood species, when used as sawtimber, can be cut to log lengths of $10,12,14,16$, or 18 feet. Both total and merchantable heights can be measured with various tools, but clinometers are generally most efficient. Clinometers use geometric functions to determine tree height by measuring angles from eye level to the tree base and crown at a fixed distance from the tree. Tree height can then be calculated based on the tangent of these measurements. These videos will help you learn to use a clinometer to measure tree height: www. youtube.com/watch? $\mathrm{v}=\mathrm{q} 4$ LhwniXAJI\&list=PLr5M0QvUoA elldKnwLvt9EF5lEtzolyTw\&index=14

www.youtube.com/watch?v=EWKC0sM82Ak\&list=PLr5M 0QvUoAel1dKnwLvt9EF51EtzolyTw\&index=5

Merchantable heights are a function of stem quality, as well as upper-stem diameter limits, which determine the last point at which the stem is usable. Accuracy in these determinations requires considerable experience in estimating upper-stem diameters from ground level with the naked eye. Foresters and land managers must become proficient in this practice to obtain accurate volume estimates.

\section{Form}

The final variable needed to calculate total tree volume is a measurement of the amount of stem taper in a tree. In general, tree diameter decreases with increasing tree height (like a cone). The environment in which a tree exists can influence the rate at which this taper occurs. For example, trees grown in close proximity to competitors (e.g., in a plantation) will tend to taper less than those grown in open areas. The characterization of this rate of taper is referred to as form class and is primarily expressed using the Girard form class. To determine Girard form class, the inside bark diameter at the top of the first log is expressed as a percentage of DBH. For example, if a tree has a 16.0-inch DBH and is 12.8 inches (inside bark diameter) at the top of the first $\log$, the form class would be 80 (i.e., $100^{\star} 12.8 / 16=100^{\star} 0.8$ ). This upper diameter measurement is taken at a height of 17.3 feet to accommodate a one-foot stump and 0.3 feet of log trimming. Form class measurements for southern pine plantations generally range from 78 to 82 . Although this four-percent difference in form class seems miniscule, a three-percent change to merchantable volume can be attributed to a one-percent difference in form class (Avery and Burkhart 2002). In other words, even a small mistake in form class can result in a large error when merchantable volume is calculated. To ensure accuracy when determining form class for a stand, it is recommended that a small subsample of trees be carefully measured to determine the form class for the entire stand.

\section{Determining Tree Volume and Weight}

The measurements discussed in the paragraphs above must be accompanied by a method for generating actual tree volumes. To standardize an estimate for how much wood is being transferred in a transaction for buyers and sellers, log rules were developed (e.g., Doyle, Scribner, International) to estimate the amount of usable wood in a $\log$ that is available for lumber production. Tables derived from these log rule equations were established for quick and efficient calculations of wood volumes generated from a cut log, measured in board feet. One board foot is defined as 12 inches x 12 inches x 1 inch thick, or 144 cubic inches. More recently, a large portion of the forest industry utilizes tonnage, or weight of timber, as the primary trading parameter, especially for pine products. Much of the coastal plain of the Southeast, where southern pine species (e.g., loblolly, slash, shortleaf, and longleaf pines) are predominately grown, uses tonnage for buying and selling timber. Estimates of tonnage can be obtained through equations designed to convert volume estimates into weight.

\section{Log Rules}

Log rules use measurements like inside bark diameter and length of a log to determine wood volume in a log and then attempt to account for wood deductions lost in the manufacturing of lumber. The volume estimates generated by the log rule are commonly given in board feet, or the amount of usable one-foot by one-foot by one-inch sections in a $\log$. Although numerous log rules have been developed, the Doyle, Scribner Decimal C, and International 1/4 rules are most commonly used in the United States. The two older log rules, Doyle (developed in 1825) and Scribner (developed in 1846), tend to be less accurate when compared to the International 1/4 log rule (developed in 1906).

To illustrate the implementation of log rule equations, a sixteen-foot $\log$ with a diameter (D) measuring 14 inches and an inside bark diameter of 10 inches at the small end of the log will be used. By inputting these variables into the equations in the table above, the subsequent board feet estimated by each log rule can be calculated. According to the International $1 / 4$ rule, this $\log$ produces roughly 71.5 board feet. When calculating the volume of the same log using 
Scribner Decimal C and Doyle rules, it will only produce 55 board feet and 36 board feet, respectively. For this reason, it is critical to know when you are buying or selling timber which log rule is being used to calculate volume. It can have a great impact on the final timber value.

To facilitate the efficient application of various log rules, tables have been created to allow foresters use measurements of DBH and height and apply the log rule of choice. To increase the accuracy and effectiveness of these tables, Girard form class is often coupled with a particular log rule in the formation of these tables. As a result, foresters can determine the stand's form class and then locate the table for that particular form class that also uses the log rule of choice. The log table below uses the International $1 / 4 \log$ rule and a Girard form class 80.

\section{Weight Equations}

Today, pine tends to be sold in tons vs. volume (board feet for sawtimber, cords for pulpwood), so weight equations have been developed based on the specific gravity and moisture content of wood. According to Avery and Burkhart (2002), the following equation can be used to determine the weight of a cubic foot of wood across all species: Density $=$ specific gravity ${ }^{*} 62.4(1+[\%$ moisture content/100]).

This process can be demonstrated by analyzing an acre of slash pine (Pinus elliottii) timber with specific gravity and moisture content in a real-world example provided by Avery and Burkhart (2002). The measured specific gravity of slash pine was 0.52 and the moisture content $120 \%$. By inputting these numbers into the equation above, the weight of a cubic foot of slash pine timber equals 71.4 pounds, $\left(0.52^{\star} 62.4[1+(120 / 100)]\right)$. Now the number of cubic feet that will be harvested in the acre of slash pine can be multiplied by the weight of a single cubic foot. If this acre produced 864 cubic feet of solid wood, the corresponding weight equals $61,689.6$ pounds (71.4 pounds/ cubic foot ${ }^{*} 864$ cubic feet). This number would commonly be expressed in tons as roughly 31 tons per acre.

Other quick conversion factors have been developed to streamline the process of converting volume to weight. The South Carolina Forestry Commission estimates that one cord $\left(128 \mathrm{ft}^{3}\right)$ of pine pulpwood is roughly 5,350 pounds, or 2.675 tons. One thousand board feet of pine sawtimber is estimated to be between 7.50 and 7.75 tons. While these simple conversions are useful for rough estimates of harvestable tonnage, precise measurements can only be obtained from accurate measurements of specific gravity and moisture content. Small changes in moisture contents can create large miscalculations of estimated weights. That said, moisture content can vary in a tree daily, and more significantly on a seasonal basis, so the heuristics (rules of thumb) above are commonly used.

\section{Stand Level Inventory}

The previous sections focused on individual trees and methods for determining wood volume in those trees. To apply this knowledge to stand-level estimations, foresters must evaluate a sample of trees within a stand. The volume of each of the sample trees can be determined, and average volume for the stand can be estimated using an expansion factor that projects the sampled averages to stand-level metrics. This process is used to analyze stands for a variety of objectives, including financial planning, stand management, habitat suitability, and development of silvicultural prescriptions.

To determine the method by which the timber estimate or "cruise" will be implemented, several factors must be considered. Cruises can be conducted with varying levels of accuracy depending on how the results will be used and the amount of money that will be invested in the cruise. The more individual trees measured in the cruise, the more closely the results will portray the actual stand. However, sampling individual trees requires time, resulting in increased costs. While accuracy levels can vary, the cruising technique must measure enough of the population to reflect a statistically significant estimate of the true values of the stand. Without reasonable precision, the results and the time spent gathering the input data are of little value. Finally, the technique by which the cruise will be conducted must be determined. This includes decisions such as plot type, size, and sampling design. Should variable- or fixedradius plots be used? Would stratified random samples or grid systems work better for this situation? These types of questions must be answered to design the proper cruising plan for meeting predetermined objectives.

\section{Cruise Type}

When determining the type of cruise to design for a particular forest, the stand characteristics must be taken into consideration. Differing soils, habitats, terrain, and density can all influence the composition of a timber stand and affect the cruising technique that is most suitable. Simple random samples may be necessary when the variability is relatively consistent throughout the stand. To achieve a truly random selection, it is essential that, to quote Avery and Burkhart, "the selection of a particular unit be in no 
way influenced by the other units that have been selected or will be selected" (2002). Sampling locations may fall adjacent to one another with this method, as long as the minimum number of samples is statistically efficient and samples are random and representative of the stand.

For forests with stands that contain more clustered variability, for example, a 100-acre block that has three distinct stand types, a stratified random sample may be more suitable. Simply put, stratified samples are like many small simple random samples within a stand. An example of the utilization of this method is outlined by analyzing a forest with stands encompassing a sandhill, a cypress pond, and flatwoods habitats. Rather than establish plots through a simple random sample across the entire forest, a stratified sample creates three distinct sampling areas: sandhill, cypress, and flatwoods. By sampling these strata independently of each other, a more accurate estimate of each stand can be gathered, and therefore a more accurate assessment of the entire forest.

The tendency to grow many timber species in plantation settings provides the opportunity to use another systematic sampling method that is set up through the development of a grid system. These uniform timber stands vary little in spacing and density across the stand, but random sampling is still a necessary practice. Cruises that implement grid techniques are defined by set distances between plot locations. For example, a $2 \times 5$ chain grid cruise (chain $=66 \mathrm{ft}$ ) is commonly used on small stands ( $<50$ acres) to determine plot centers and corresponds to one plot per acre. The size of the tract of land you are cruising and the desired intensity (i.e., the \% of the land measured) will help determine what the grid spacing will be for any particular cruise. Common grid increments include $2 \times 5-1$ plot/acre, $5 \times 10$ - 1 plot $/ 5$ acres, $5 \times 20-1$ plot/10 acres, $10 \times 20-1$ plot/20 acres. Clearly, as the size of the grid spacing increases, each plot begins to represent a greater area and, subsequently, more trees. This is one component of the expansion factor that will allow one to go from individual plot-level calculations of volume to stand-level estimates.

\section{Plot Size and Type}

Determining the size of sample plots is largely related to the stand characteristics of the area being cruised. Plots should be adequately sized to manage labor and time inputs while effectively accounting for the variability in the stand. For example, if the area being sampled is a seed tree cut twelve years after harvesting, the stand will be comprised of many small trees and a few scattered large ones. A few small plots may not adequately represent the area because the large, scattered trees may be excluded or poorly represented in the sample. As a result, either plot size or the number of plots must be increased to accurately sample the area. Stand density also plays a major role in determining plot size. Denser stands usually require smaller plots because several individuals must be measured in each sample plot, and they are closer to the plot center. Furthermore, this allows the cruiser to easily access the sample specimens. For open grown stands, larger plots may be more easily managed and can reduce sampling time and effort while still accounting for the variability within the stand. Generally, the denser and less variable a stand is, the smaller the plot size needed. Open forests, such as natural longleaf pine (Pinus palustris) habitats, may require plots as large as $1 / 5$ acre because of the distances between individual trees.

For fixed-area plots, which are plots with a predetermined area, each tree measured represents multiple trees on that given acre. For example, if using a $1 / 5$-acre plot, then each tree measured on that plot represents 5 trees on that acre. In the case of a 1/10-acre plot each tree represents 10 trees. Therefore, it is easy to see how important it can be to be diligent in measuring only trees that are actually "in" or within the boundaries of the plot, because adding or missing a tree can contribute greatly to error in estimates. As a general rule of thumb, with fixed-area plots you will measure 10-15 trees.

The expansion factor for fixed-area plots is thus made up of two variables, the number of acres each plot represents and the number of trees each measured tree represents. To illustrate, each tree measured on a 1/10-acre sized plot would represent 10 trees. A 1/10-acre plot with three trees of 6-, $12-$, and 28-inch DBH would be expanded to represent 30 trees per acre. Specifically, it would represent 106 -inch DBH trees, 10 12-inch DBH trees, and 1028 -inch DBH trees). If the spacing of these plots was on a $5 \times 10$ chain grid ( 1 plot $/ 5$ acres), this plot ( 3 measured trees) would represent a total of 150 trees in this 5 -acre stand. Volume estimations can be determined through the same process. If the volume estimate for the $1 / 10$-acre plot was 650 board feet, corresponding per-acre volume would be 6,500 board feet/acre $(10 * 650$ board feet). Because the plot represents 5 acres ( $2 \times 5$ chain grid), the plot represents 6,500 board feet/ acre times 5 acres or a total of 32,500 board feet. The same process is used across all fixed-area plots in the stand to calculate a total volume estimate.

Not all cruising techniques use a predetermined plot size. Rather, alternative techniques use variable-area plots in which plot size is a factor of the size of the sample trees. An instrument known as prism is often used to identify 
individual sample trees in variable-area plots leading some to refer to this technique as prism cruising. By creating a visual illusion in which a section of the tree is offset from the rest of the stem, the cruiser can determine if the tree lies within the plot. The larger the tree diameter, the greater the distance the tree can lie from the plot center while still being included in the plot and vice versa for smaller diameters. The result of this method is that a greater number of large trees are measured in the sample in relation to small trees. Larger trees are responsible for a greater percentage of the volume (and often are the most valuable ones), so this method targets those trees that contribute most to total volume estimations (Wenger 1984). Expansion factors for prism plots are based on the basal area factor (BAF) of the prism (or the instrument used) and the size of the tree measured. The following video is useful for learning more about prism cruising: www.youtube.com/watch? $\mathrm{v}=\mathrm{nhzTpvE}$ T_7M\&list=PLr5M0QvUoAel1dKnwLvt9EF5lEtzolyTw

\section{Cruising for Statistical Precision}

While designing a cruising plan, it is necessary to set some level of accuracy as the goal for the cruise. This accuracy level is determined by factors ranging from the forester's opinion to the objective for the cruise and, most importantly, the budget. A cruise that is more accurate than necessary will expend more time, effort, and funding than necessary to accomplish the goal of the cruise. The key point is that both inaccurate and overly accurate cruising designs result in a waste of resources. A number of equations can be used by foresters to determine the number of plots needed for a statistically accurate cruise, so professional foresters must be adept at understanding the statistical basis for estimating inventory and the financial constraints associated with the time and labor required to meet the objective.

\section{Product Classes}

When conducting a cruise, it is not only necessary to determine the volume within a stand but to analyze the quality of the product as well. Two different stands may have similar amounts of total standing volumes but vary greatly in the value of the crop that has been grown. For example, a stand that has been thinned and is now composed of fewer large trees may have only slightly more cubic feet than an unthinned stand with many small trees. However, the former stand is valued much higher because of the superiority of the product. Accurately identifying products in a timber stand is an important component of any timber cruise.
In the Southeast, most of the softwood traded in the markets can be divided into three major classes: pulpwood, chip-n-saw, and sawtimber. Two other common product categories are poles and plylogs. Sawtimber, poles, and plylogs require specific diameter, form and straightness and tend to command a higher value. Pulpwood is generally composed of the smallest trees or larger trees that exhibit substantial deformities such as knots, crooks, and cankers. Southern pines grown for pulpwood can be grown on the shortest rotation lengths and can be harvestable as early as age 12 on the most productive sites, but are usually harvested between ages 15 and 20. Generally, trees sold as pulpwood range from 4 to 8 inches $\mathrm{DBH}$ and are the primary product in many areas of the Southeast. The value of pulpwood tends to be the lowest of all classes.

Chip-n-saw ranges from about 8 to 10 inches $\mathrm{DBH}$ and represents the smallest trees used to manufacture lumber. These trees are used in the production of $2 \times 4$ boards, primarily used in the framing of houses. Chip-n-saw and pulpwood are the usual product classes harvested in the first and second thinnings of a timber stand. Subsequent thinnings and final harvests provide opportunities for harvesting the larger sawtimber products.

Trees 10 inches and greater can be harvested as sawtimber provided the tree bole meets quality specifications. Sawtimber trees can be used in the manufacture of both grade lumber and veneer used in plywood. The longer rotations required for growing sawtimber or other higher-valued products are rationalized by the nearly tripled stumpage price when compared with pulpwood.

To determine the value of a timber stand through cruising, the categorization of these different products is essential for accurate estimations of potential profit. The importance of product distinction necessitates the use of an experienced forester when contracting the cruising of a timber stand. If the quality of the standing timber is valued incorrectly based on product classes, the expected revenue from the harvesting operation could be severely miscalculated.

\section{Summary}

Ultimately, timber cruising combines several disciplines to provide insight into the amount of volume and relative value of a timber stand. Each component, whether biological, statistical, or economic is dependent on the others for synthesizing data and providing beneficial results from a cruise. Furthermore, to generate accurate estimates of 
timber volumes and potential revenue for financial planning or management guidelines, an experienced forester with extensive knowledge of evaluating individual trees and a thorough understanding of timber market dynamics should be consulted.

\section{Literature Cited}

Avery, T. E., and H. E. Burkhart. 2002. Forest Measurements (5 ${ }^{\text {th }}$ ed.). New York, NY: McGraw- Hill.

Bond, B. 2011. "Understanding Log Scales and Log Rules." Retrieved from https://utextension.tennessee.edu/publications/documents/pb1650.pdf.

Freese, F. 1962. "Elementary Forest Sampling." U.S. Department of Agriculture Handbook 232. Washington, D.C.:

Government Printing Office.

Husch, B., C. I. Miller, and T. W. Beers. 1982. Forest Mensuration ( $3^{\text {rd }}$ ed.). New York, NY: John Wiley \& Sons.

South Carolina Forestry Commission. (n.d.). "Understanding Timber as a Commodity." Retrieved from http://www. state.sc.us/forest/lecom.htm.

Wenger, K. F. (ed.). 1984. Forestry Handbook ( $2^{\text {nd }}$ ed.). New York, NY: John Wiley \& Sons. 
Table 1. Log rule equations for Doyle, Scribner Decimal $C$, and International $1 / 4 ; D=$ inside bark diameter at small end of log, $B F=$ board feet and $L=$ log length.

\begin{tabular}{|l|l|}
\hline \multicolumn{1}{|c|}{ Log Rule } & \multicolumn{1}{c|}{ Equation for 16-foot Logs } \\
\hline Doyle & Log Volume $(B F)=.(D-4)^{2}$ \\
\hline Scribner Decimal C & Log Volume $(B F)=.\left(0.79 D^{2}-2 D-4\right) L / 16 ;$ \\
\hline International $1 / 4$ & For $16-f o o t ~ l e n g t h s: ~ B F=\left(0.88 D^{2}-1.52 D-1.36\right)$ \\
\hline Source: Husch, Miller, and Beers (1982) & \\
\hline
\end{tabular}

Table 2. Volume estimates (measured in board feet) by DBH; International 1/4 log rule, Girard form class 80.

\begin{tabular}{|c|c|c|c|c|c|c|c|c|c|c|c|}
\hline \multicolumn{12}{|c|}{ Merchantable Tree Height (16-foot Logs) } \\
\hline DBH (in.) & 1 & 1.5 & 2 & 2.5 & 3 & 3.5 & 4 & 4.5 & 5 & 5.5 & 6 \\
\hline 10 & 39 & 51 & 63 & 72 & 80 & - & - & - & - & - & - \\
\hline 12 & 59 & 78 & 98 & 112 & 127 & 136 & 146 & - & - & - & - \\
\hline 14 & 83 & 112 & 141 & 164 & 186 & 201 & 216 & - & - & - & - \\
\hline 16 & 112 & 151 & 190 & 223 & 256 & 280 & 305 & - & - & - & - \\
\hline 18 & 144 & 196 & 248 & 292 & 336 & 369 & 402 & - & - & - & - \\
\hline 20 & 181 & 248 & 314 & 370 & 427 & 470 & 512 & 546 & 580 & - & - \\
\hline 22 & 221 & 304 & 387 & 458 & 528 & 583 & 638 & 685 & 732 & - & - \\
\hline 24 & 266 & 368 & 469 & 556 & 644 & 708 & 773 & 836 & 899 & - & - \\
\hline 26 & 315 & 436 & 558 & 662 & 767 & 849 & 931 & 1,008 & 1,086 & - & - \\
\hline 28 & 367 & 510 & 654 & 779 & 904 & 1,000 & 1,096 & 1,190 & 1,284 & 1,368 & 1,453 \\
\hline 30 & 424 & 591 & 758 & 904 & 1,050 & 1,161 & 1,272 & 1,388 & 1,503 & 1,613 & 1,723 \\
\hline
\end{tabular}

